\title{
Parameters Development for Optimum Deposition Rate in Laser DMD of Stainless Steel EN X3CrNiMo13-4
}

\author{
Mohammad Dalaee ${ }^{1,2}$ (1) Eduardo Cerrutti $^{1} \cdot$ Indira Dey $^{1,2}$. \\ Christian Leinenbach ${ }^{3} \cdot$ Konrad Wegener $^{1}$
}

Accepted: 22 November 2021 / Published online: 1 December 2021

(c) The Author(s) 2021

\begin{abstract}
Laser Direct Metal Deposition (DMD) has been developed as a manufacturing process to deposit coatings on existing materials and proves advantageous in Additive Manufacturing (AM) of complex and precise components. However, it is necessary to carefully determine the proper process parameter combinations to make this method economically viable for industries. The intent of this study is to address enhancement in productivity of laser DMD of stainless steel EN X3CrNiMo13-4. Accordingly, the effects of the main laser process parameters of laser power $P$, scan speed $v$, powder flow rate $\dot{\mathrm{m}}$, and spot diameter $s$ on track geometries and buildup rate are discussed. The regression analysis is conducted to derive correlations between the combined set of main parameters and deposition rate. The results show a good linear regression correlation of $\mathrm{R}^{2}>0.9$ for the geometrical characteristic of aspect ratio, dilution, and deposition rate. The constructed processing map, using linear regression equations, presents proper process parameters selection in connection with deposition rate, aspect ratio, and dilution rate.
\end{abstract}

Keywords Laser direct metal deposition · Parameters optimization · Laser cladding · Additive manufacturing

\footnotetext{
Highlights

- Approaches to figure out the optimum laser parameter combinations at a given laser power concerning deposition rate.

- Process map specifies the operating region for deposition of a layer without bonding errors, and at the maximum deposition rate.
}

Mohammad Dalaee

Dalaee@inspire.ethz.ch

Extended author information available on the last page of the article 


\section{Introduction}

In Laser Direct Metal Deposition (DMD), the laser beam melts the powder feedstock and a thin layer of the metallic substrate and generates a melt pool of powder and substrate materials. Thus a layer of metal is deposited on the substrate during relative movement between the substrate and the laser nozzle $[1,2]$. The powder particles are delivered into the melt pool by carrier gas, and the melt pool is protected from oxidation by a shielding gas. One of the main applications of laser DMD is additive manufacturing (AM) of complex components [3-5]. For AM of parts with high-resolution, a coaxial powder nozzle setup is required. Singh et al. [6] presented a comprehensive review of key technologies used for powder feedstock handling in laser DMD, including types of powder feed nozzles and their advantages and limitations. The required laser power depends on the material properties and the targeted deposition rate. The productivity is essential in AM of large metallic components to make the laser DMD method economically beneficial for industries. In the previous publications [7, 8], the potential integration of laser DMD technology with existing technologies was studied, aiming to enhance the deposition rate. However, the first and crucial step in this subject is to set the main processing parameters to obtain optimum parameter combinations, resulting in a maximum achievable deposition rate for the specific laser power.

The operation windows for the DMD process are typically defined by four main factors, including the laser power $P$, the scan speed $v$, the powder flow rate $\dot{\mathrm{m}}$, and the spot diameters. Numerous researches have been conducted to investigate the effect of these key parameters on clad geometry and material integrity of the deposited materials. Certainly, several other process parameters contribute to yield a good quality of cladding, including material properties [3, 9]. For instance, Errico et al. [10] studied the influence of $P, v, \dot{\mathrm{m}}, s$ and carrier gas flow rate on microstructure and porosity of deposited AISI 304 stainless steel. Campanelli et al. [11] examined parameters of $P, v, \dot{\mathrm{m}}$ and degree of overlapping between adjacent layers to evaluate the properties of deposited $18 \mathrm{Ni}$ (300) marage steel powder. A large number of analyses was performed by Ascari et al. [12] by investigating the effects of process parameters into the resulting dimensions, surface roughness, microstructure, hardness, tensile strength, and production time for deposited bulk from 316 L Stainless Steel.

By a high laser power without inserting sufficient powder flow, power attenuation is minimized; hence the excess laser energy is transferred to the substrate, causing a high dilution rate and low deposition efficiency. On the other hand, over powder mass flow may result in an improper aspect ratio or even a lack of fusion between the cladding and the substrate. This derangement can lead to porosities between side layers, as stated by Henry et al. [13] and Sun et al. [14]. Therefore, the initial geometry of a single track is vital in the building of defect-free overlapped tracks, as well as the productivity of multiple layers. On this account, a single track is considered as the main criterion in the process characterization in this study. The authors conclude the proper geometry of a single track in a 
definition called "Cladability," which includes building a bead at a low level of dilution, a proper aspect ratio that results in dense overlapped tracks, and in the further step, offering a maximal deposition efficiency. Figure 1 shows three types of clad cross-sections that may be deposited, as well as the geometric properties of a clad. Melt pool depth $b$ represents the depth of the substrate layer, which is molten during the deposition process. Accordingly, $A_{c}$ and $A_{m}$ are the areas of the clad and the molten substrate, respectively.

To profit from the maximum energy of the laser beam and to increase productivity, a minimum level of metallurgical bonding between the substrate and the clad layer is preferable. In other words, the highest fraction of energy input must be consumed for the deposition of the powder feedstock rather than for melting an unnecessary part of the substrate. To quantify the level of energy that is consumed for substrate melting, a dimensionless factor called dilution can be defined:

$$
D_{i}=\frac{A_{m}}{A_{m}+A_{c}}
$$

High dilution (Fig. 1A) is not preferable due to low productivity. Besides, this type of cross-section results in a large Heat Affected Zone (HAZ), which may lead to degrading mechanical properties of the layer underneath. The optimum value of dilution is generally between $10 \%$ and $30 \%$, as reported by Dass et al. [15]. The clad angle $\theta$ is an important character, as it influences the quality of the overlapping layers. This character can be linked to a dimensionless parameter called the aspect ratio $A_{R}$, which is a ratio between width $w$ and height $\mathrm{h}$ of a clad, as represented by:

$$
A_{R}=\frac{\mathrm{W}}{\mathrm{h}}
$$

In a thick clad, the $A_{R}$ is low, a clad angle $\theta$ becomes large, and dilution begins to be poor, as shown in Fig. 1C. This type of clad shape may not be suitable since many authors reported that low $A_{R}$ and dilution might lead to porosity between overlapped layers called inter-run porosity. It occurs due to a lack of sufficient energy input to fully melt the powder and the clad layer near the thick clad interface.

Cladability is primarily determined by the process parameters used during the DMD operation, as well as the specification of the DMD nozzle and compatibility of the clad and substrate materials. The scan speed $v$ and the powder feed rate $\dot{m}$ have a direct effect on productivity. Besides, the scan speed can indirectly affect productivity due to its impact on the interaction of the powder particles with the melt pool.

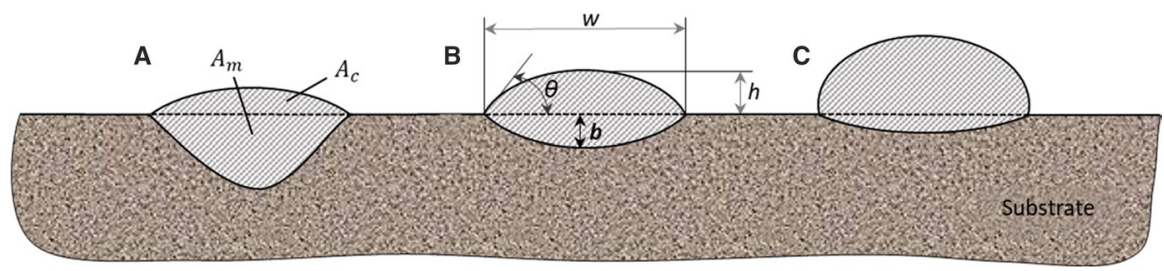

Fig. 1 A typical cross-section of a clad bead 
This effect can be quantified by a factor called powder feed per length $m_{x}$, described by:

$$
m_{x}=\frac{\dot{\mathrm{m}}}{v}
$$

However, enough energy must be delivered to the melt pool in connection with the scan speed $v$ and the powder feed rate $\dot{m}$ to achieve a dense clad. According to Toyserkani et al. [16], the input power intensity $I$ to the melt pool can be controlled through the laser power $P$ or laser spots, expressed by:

$$
I=\frac{P}{\pi(s / 2)^{2}}
$$

However, it is crucial to provide appropriate power intensity $I$ at a certain level of interaction time $t$, presented by:

$$
t=\frac{s}{v}
$$

Insufficient or excess power intensity $I$ can lead to a lack of metallurgical bonding and a high dilution rate, respectively. Several physical models have been developed to describe the laser cladding process and track geometry. For instance, Colaco et al. [17] developed a simple lumped model to estimate the correlation between width and height of clads with process parameters such as powder feed rate and travel speed. Wirth et al. [18] developed a 3D finite element simulation model using COMSOL Multiphysics software to predict the height and width of the deposited weld tracks. More recently, Mianji et al.[19] used a multi-layer finite element model (FEM) to predict the thermal cycles, maximum temperatures, and volume of the molten pool during DMD. However, Empirical-statistical methods can offer an exploration into process-clad geometries relationship to avoid analyzing complex physical phenomena of the process. For instance, Ansari et al. [20] investigated statistical correlations between process parameters $P, v, \dot{\mathrm{m}}$, and the final geometry of the single tracks, using NiCrAlY powder on a Nickel-based superalloy. Li et al. [21] used the same approach to construct a processing map for laser deposition of 85 wt $\% \mathrm{Ti}+15 \mathrm{wt} \%$ TiBCN Powder on 7075 Aluminum Alloy Substrate. In another work, Pacheco et al. [22] developed an empirical statistical model to determine the optimized parameters for depositing Stellite-6 powder on AISI 316 L austenitic stainless steel. In Bax et al. [23], the relationship between process parameters of $P$, $v, \dot{\mathrm{m}}$ and output results of track geometry and built-up rate for Inconel 718 powder were analyzed. The Authors indicated that dilution and build rate do not directly depend on scanning speed. However, experimental evidence in other studies [22, 24] demonstrates a direct correlation between these factors. The influence of process combination of $P, v, \mathrm{~s}$ on the geometry and integrity of deposited single track (the presence of pores) for WC-12Co powder on AISI 321 stainless steel has been evaluated by Erfanmanesh et al. [25].

In this study, the goal is to determine the effects of the main process parameters on the clad properties and build-up rate in laser DMD of EN X3CrNiMo13-4 that 
was not discussed in the literature. In the first step, the influencing factors of $v, \mathrm{~s}$, and $\dot{\mathrm{m}}$ on productivity and bonding quality of the deposited tracks are discussed using the described physical equations. Afterward, the regression analysis is conducted to drive correlations between the combined set of parameters and clad geometries, as well as deposition rate. To meet this target, the Taguchi method is employed to perform the experiment's design to test a wide range of processing parameters. It allows choosing the level of parameters independent of each other and provides a great understanding of the effect of all variations on the process behavior at a relatively low number of the experiment. The correlations are established as combined process parameters $(s, v, \dot{\mathrm{m}})$ for the characteristic of the clad geometries $\left(A_{c}, A_{m}, w, h\right)$ to show the behavior of the deposition rate $\dot{\mathrm{D}}$, the aspect ratio $A_{R}$ and dilution rate $D_{i}$ as a function of main parameters. The linear regression results combined with coefficient correction factors are used to construct a processing map, aiming to provide a range of suitable parameters for depositing layers at optimum productivity and adequate cladability (i.e., low dilution rate and proper aspect ratio). This processing map is set up and validated with experiments.

\section{Materials and Experimental Details}

\section{Materials}

Stainless steel material EN X3CrNiMo13-4 (1.4313) provided by Oerlikon Metco AG is used as powder feedstock. The diameter distribution of the powder is analyzed with a manifold of approximately 10,000 particles. The powder particles have a size of $40-110 \mu \mathrm{m}$ with particle size distribution shown in Fig. 2A. The average particles diameter is $90 \mu \mathrm{m}$. The powder morphology is analyzed by scanning electron microscopic (SEM) FEI NanoSem $20 \mathrm{KeV}$. Particles appear to be spherical and can be described as dense, as shown in Fig. 2B.

A structural steel S235JRC + C substrate with a size of $30 \times 8 \times 100 \mathrm{~mm}^{3}$ is used for the deposition of layers. The experiments are carried out on the Trumpf TruLaser Cell 7020 CNC machine, using a Trumpf TruDisk 3001 ytterbium-doped
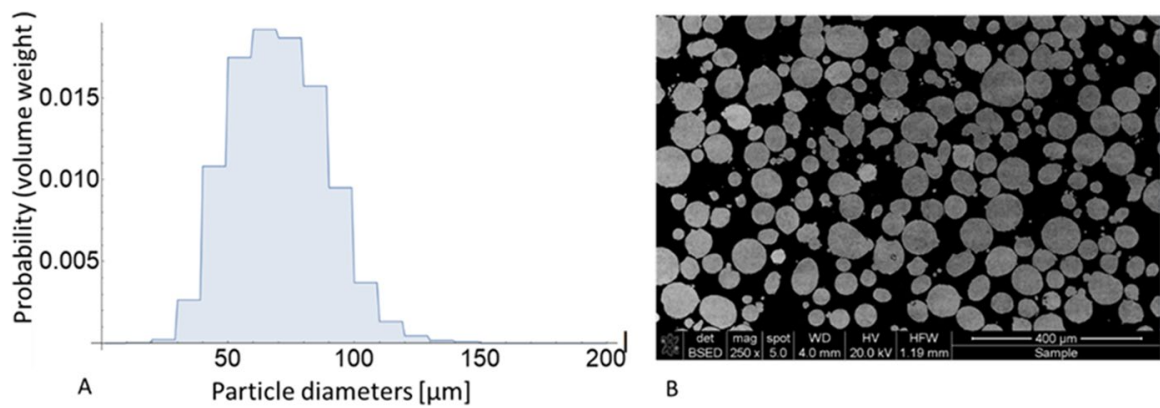

Fig. 2 Measurement result of powder stainless steel EN X3CrNiMo13-4. Panel A and B show powder size distribution and SEM images of powder particles, respectively 
yttrium aluminum garnet (Yb: YAG) disk laser with a wavelength of $1030 \mathrm{~nm}$. The maximum output of laser power is $3 \mathrm{~kW}$. The powder is fed by an in-house three-jet powder nozzle from Oerlikon Metco AG. Argon is used as a carrier gas and shielding gas at a flow rate of $7.5 \mathrm{~L} / \mathrm{min}$ and $15 \mathrm{~L} / \mathrm{min}$, respectively. The powder feed rate is calibrated prior to each experimental test, considering the rotational speed of the dosing disk in the powder feeder. The cross-sectional area of fabricated samples is polished and etched with Adler etchant to visualize the melt penetration depth in the substrate. The micrographic images are taken using Keyence Microscope VHX 5000, with a magnification of 200×.

\section{Experimental Procedure}

A Taguchi experimental design method is used to examine the processing parameters range of the material EN X3CrNiMo13-4. The key variable parameters of scan speed $v$, spot diameter $\mathrm{s}$, and powder feed rate $\dot{\mathrm{m}}$ are examined. The output powder feed rate of the nozzle is calibrated before each experiment. A fixed laser power of $1200 \mathrm{~W}$ is considered to analyze the proper range of spot diameter at a given laser power. The typical parameters of the laser DMD process are employed to have the distinctive qualities of parameters. The specific range of $v(600-1400$ $\mathrm{mm} / \mathrm{min}$ ) is employed with a step interval of $400 \mathrm{~mm} / \mathrm{min}$. A typical range of laser intensity $\left(I=100-200 \mathrm{~W} / \mathrm{mm}^{2}\right)$ is used to calculate the approximate range of spot diameter at the given laser power. Correspondingly, the spot sizes of $2 \leq$ $\mathrm{s} \leq 3 \mathrm{~mm}$ are used. The powder feed rates of $9 \mathrm{~g} / \mathrm{min}, 15 \mathrm{~g} / \mathrm{min}$, and $21 \mathrm{~g} / \mathrm{min}$ are

Table 1 Process parameter combinations in the experiment plan

\begin{tabular}{llllllll}
\hline Sample No. & $\begin{array}{l}\text { Spot } \\
\text { size } s \\
{[\mathrm{~mm}]}\end{array}$ & $\begin{array}{l}\text { Scan speed } \\
v[\mathrm{~m} / \mathrm{min}]\end{array}$ & $\begin{array}{l}\text { Powder feed } \\
\text { rate } \mathrm{m}[\mathrm{g} / \\
\mathrm{min}]\end{array}$ & Sample No. & $\begin{array}{l}\text { Spot } \\
\text { size } s \\
{[\mathrm{~mm}]}\end{array}$ & $\begin{array}{l}\text { Scan speed } \\
v[\mathrm{~m} / \mathrm{min}]\end{array}$ & $\begin{array}{l}\text { Powder feed } \\
\text { rate } \mathrm{m}[\mathrm{g} / \\
\mathrm{min}]\end{array}$ \\
\hline 1 & 2.5 & 1 & 9 & 15 & 3 & 0.6 & 21 \\
2 & 2.5 & 1 & 15 & 16 & 3 & 1.4 & 9 \\
3 & 2.5 & 1 & 21 & 17 & 3 & 1.4 & 15 \\
4 & 2.5 & 0.6 & 9 & 18 & 3 & 1.4 & 21 \\
5 & 2.5 & 0.6 & 15 & 19 & 2 & 1 & 9 \\
6 & 2.5 & 0.6 & 21 & 20 & 2 & 1 & 15 \\
7 & 2.5 & 1.4 & 9 & 21 & 2 & 1 & 21 \\
8 & 2.5 & 1.4 & 15 & 22 & 2 & 0.6 & 9 \\
9 & 2.5 & 1.4 & 21 & 23 & 2 & 0.6 & 15 \\
10 & 3 & 1 & 9 & 24 & 2 & 0.6 & 21 \\
11 & 3 & 1 & 15 & 25 & 2 & 1.4 & 9 \\
12 & 3 & 1 & 21 & 26 & 2 & 1.4 & 15 \\
13 & 3 & 0.6 & 9 & 27 & 2 & 1.4 & 21 \\
14 & 3 & 0.6 & 15 & & & & \\
\hline
\end{tabular}


employed. Based on this method and given variable levels, a total of 27 different single tracks are deposited. Table 1 shows the matrix of selected variables for each sample.

The fabricated samples are cross-sectioned, and clad geometries analyzed, including $A_{c}, A_{m}, w$, and $h$. The deposition rate $\dot{\mathrm{D}}$ is measured according to the weld clad area, governed by

$$
\dot{\mathrm{D}}=v A_{c} \rho
$$

where $\rho$ is the density of the examined material. The dilution $D_{i}$ and aspect ratio $A_{R}$ are calculated from Eqs. (1) and (2), described in Sect. 1

A linear regression method is developed using MATLAB software to correlate the clad geometry $\left(A_{c}, A_{m}, A_{R}\right)$ as well as $\dot{\mathrm{D}}$ against a combination of process parameters $f(s, v, \dot{\mathrm{m}})$, given by:

$$
Y=a X+b, X=s^{\alpha} v^{\beta} \dot{\mathrm{m}}^{\gamma}
$$

for $2 \leq s \leq 3[\mathrm{~mm}]$ and $600 \leq v \leq 1400[\mathrm{~mm} / \mathrm{min}]$ and $9 \leq \dot{\mathrm{m}} \leq 21[\mathrm{~g} / \mathrm{min}]$. The combined parameter $\mathrm{X}$ is established from optimizing the exponents $\alpha, \beta, \gamma$ to maximize the regression coefficient $\mathrm{R}^{2}$.

\section{Results and Discussion}

\section{Process Development for Optimum Deposition Rate}

Figure 3 shows cross-sectional optical micrographs of the single clad tracks of all 27 fabricated samples at a laser power of $1200 \mathrm{~W}$ and different process combinations of scan speed $v$, powder feed rate $\dot{m}$, and spot size $s$. Accordingly, the results of the clad width and height are plotted in Fig. 4 to analyze the geometrical characteristics of the single track in connection with the laser process parameters. It can be seen that increasing the scan speed leads to a reduction of the clad thickness. However, the influence is more substantial in the speed range of $600-1000 \mathrm{~mm} / \mathrm{min}$ compared to

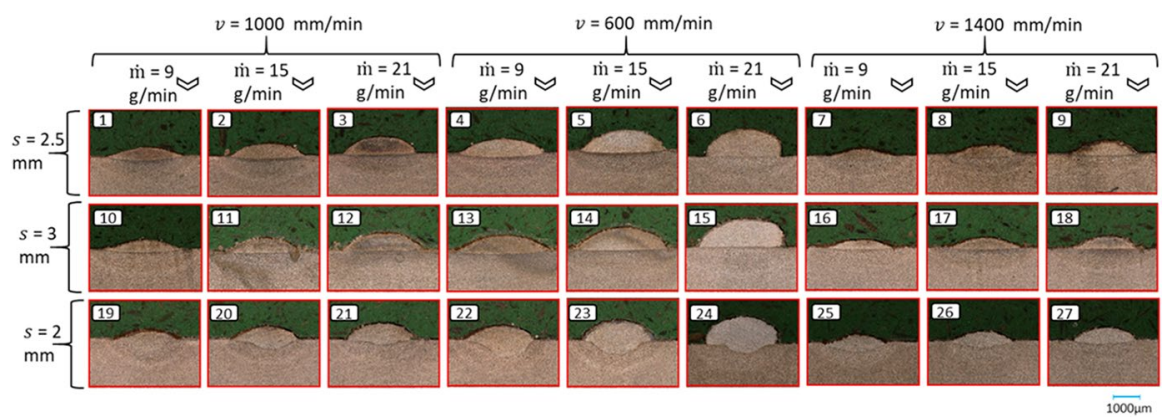

Fig. 3 Optical micrographs of the single track cross-sections at different process parameter combinations 

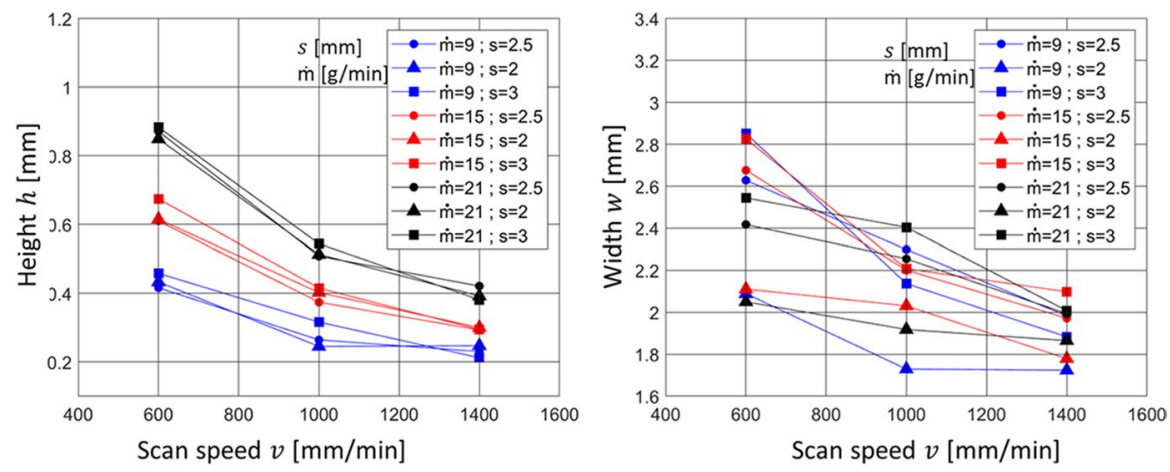

Fig. 4 The clad height $h$ and width $w$ as a function of scan speed $v$ at three levels of spot sizes $s$ and powder feed ratee $\dot{m}$

the range of $1000-1400 \mathrm{~mm} / \mathrm{min}$. It may stem from the lowering of the interaction of the powder particles with the melt pool, according to Eq. (3). Increasing the powder feed rate has a minor effect on the clad width at the constant laser spot diameter and scan speed, but conceivably, a major influence on the clad height. Increasing the scan speed also leads to downsizing of the tack width (cf. Fig. 4B). This can be a reflection of the diminution in the lateral heat conduction of the melt pool owing to the reduction of laser interaction time.

Figure 5 shows the laser power intensity versus the interaction time of the samples produced at three levels of powder feed rates and spot diameters. The samples are grouped in the graph based on the cladabilty definition, according to the measurement results of cross-sectioned samples in which clad with lack of metallurgical bonding $(b \leq 0.05 \mathrm{~mm})$ and with a high dilution $(\geq 50 \%)$ are designated as a bonding error and a dilution error, respectively. The samples with strong metallurgical bonding but with dilution below $50 \%$ are shown as having adequate cladability. The main aim of this classification is to characterize the proper value of laser intensity as a function of the interaction time for the processing of the material. The laser intensity ranges are $169.8 \mathrm{~W} / \mathrm{mm}^{2}, 244.5 \mathrm{~W} / \mathrm{mm}^{2}$, and $382 \mathrm{~W} / \mathrm{mm}^{2}$, referring to $3 \mathrm{~mm}$, $2.5 \mathrm{~mm}$, and $2 \mathrm{~mm}$ spot sizes, respectively. The interaction time is between $0.107 \mathrm{~ms}$ to $0.3 \mathrm{~ms}$.

By comparing the diagrams, it can be seen that at the laser intensity of $382 \mathrm{~W} /$ $\mathrm{mm}^{2}$ and at the interaction time above $0.1 \mathrm{~ms}$, samples were fabricated with a dilution error, even at the maximum level of the powder feed rate $(21 \mathrm{~g} / \mathrm{min})$ (cf. Fig. 5C). However, at the interaction of $0.085 \mathrm{~ms}$ and powder feed rate $\geq 15 \mathrm{~g} / \mathrm{min}$, there is a correspondingly less thermal effect on the target substrate, resulting in adequate cladability in samples N.26 and N.27 with a dilution of $40.2 \%$ and $24.4 \%$, respectively. The dilution in sample N.25 is $63.4 \%$.

The laser intensity $I$ level of $244.5 \mathrm{~W} / \mathrm{mm}^{2}$ supplies sufficient energy for the bonding of the clad and the substrate at the powder feed rates of $9 \mathrm{~g} / \mathrm{min}$ and $15 \mathrm{~g} / \mathrm{min}$ (cf. Fig. 5A\&B). However, there is a bonding error at the powder mass flow of $21 \mathrm{~g} / \mathrm{min}$ due to the relatively higher level of laser power attenuation by the powder particles, hence the reduction of the absorbed energy level on the 

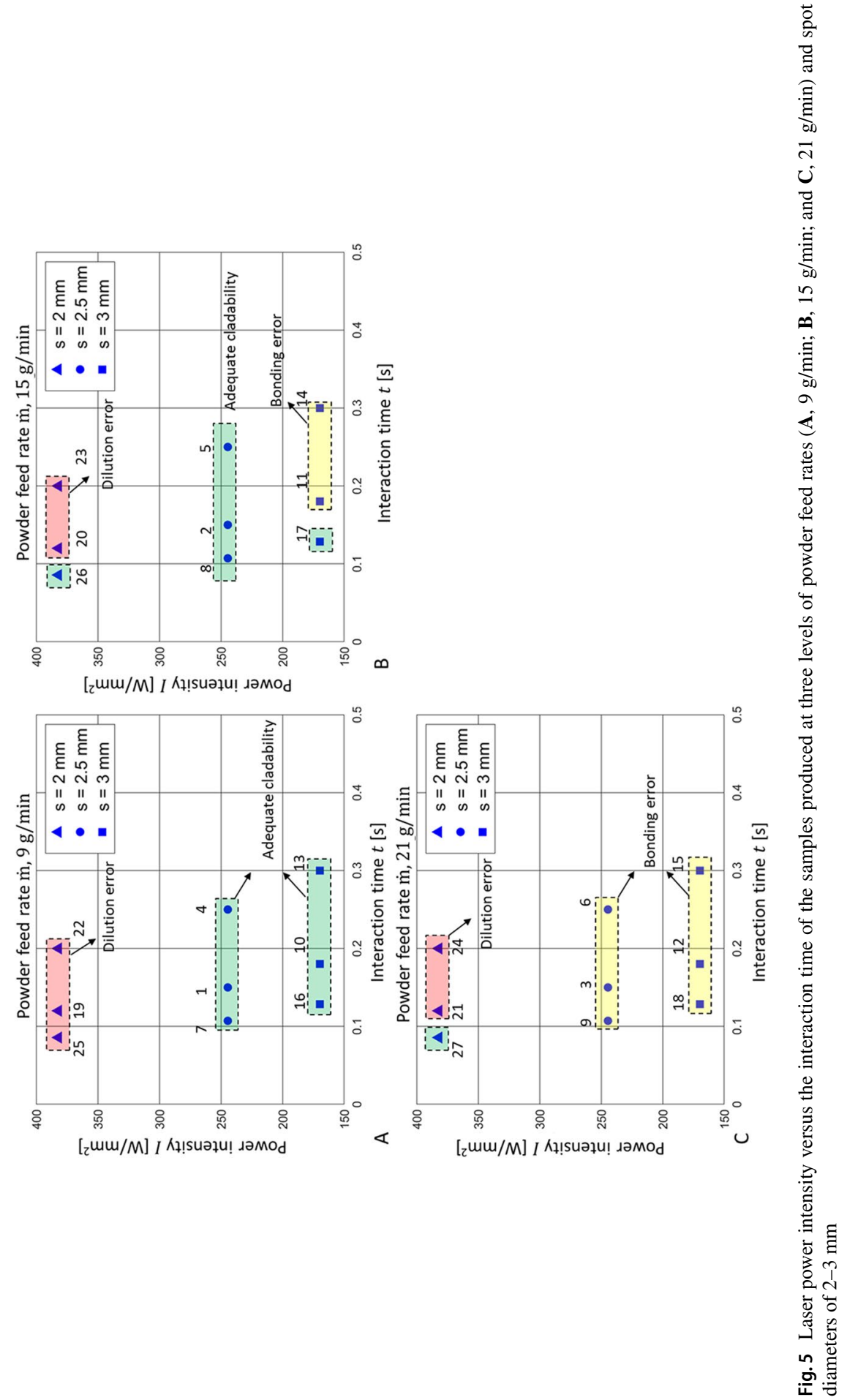
substrate. When the laser intensity level reduces from $244.5 \mathrm{~W} / \mathrm{mm}^{2}$ to $169.8 \mathrm{~W} /$ $\mathrm{mm}^{2}$ due to the increase of the spot diameter from $2.5 \mathrm{~mm}$ to $3 \mathrm{~mm}$, a bonding error occurs at the powder feed rate above $15 \mathrm{~g} / \mathrm{min}$ except for sample N.17. This result indicates that a relatively lower amount of powder can be fed into the melt pool at this level of laser intensity, which then leads to minimizing the build-up rate as a consequence.

Further analysis has been done on the samples, which are in the group of adequate cladability, to evaluate their deposition rate. Figure 6 shows the deposition rate as a function of powder feed rate as well as the aspect ratio of the fabricated samples. Sample numbers are plotted in Fig. 6A\&B. By comparing the results, as was expected, the maximum powder feed rate of $21 \mathrm{~g} / \mathrm{min}$ results in a maximum deposition rate of $0.34 \mathrm{~kg} / \mathrm{h}$ in sample N.27. However, its powder mass flow is $40 \%$ higher than sample N.5, whereas the difference in their deposition rate is only $3 \%$ (cf. Fig. 6A). This implies that the powder melting efficiency is very low with the process parameter combination in sample N.27. This is mainly due to the relatively high travel speed in the parameter set of sample N. $27(1.4 \mathrm{~m} / \mathrm{min})$ compared to sample N.5 $(1.0 \mathrm{~m} / \mathrm{min})$, which results in a lower powder feed per unit length $m_{x}(15 \mathrm{~g} / \mathrm{m}$ and $25 \mathrm{~g} / \mathrm{m}$ in samples N.27 and N.5, respectively).

This factor can also explain the results of the deposition rate in samples N.2 and N.8, in which at the same powder mass flow rate of $15 \mathrm{~g} / \mathrm{min}$ and spot size of $2.5 \mathrm{~mm}$, the deposition rate is about $20 \%$ higher in N.2 compared to N.8, as their $m_{x}$ values are $15 \mathrm{~g} / \mathrm{m}$ and $10.71 \mathrm{~g} / \mathrm{m}$, respectively. However, this factor cannot interpret the result of the build-up rate in samples N.17 and N.8 as the $m_{x}$ value in both samples are the same $(10.71 \mathrm{~g} / \mathrm{m})$, but the deposition rate is higher in the N.17. It is due to its larger spot size ( $3 \mathrm{~mm}$ vs. $2.5 \mathrm{~mm}$ ), thus larger melt pool size, which increases the powder particles catchment efficiency. In conclusion, samples N.5 and N.2 exhibit the most suitable process parameter combination for the deposition of a single track among the other samples based on the deposition rate and the powder melting efficiency criterion. The aspect ratio of sample N.2 is higher than N.5 (cf. Fig. 6B), which may be recognized as an advantage due to
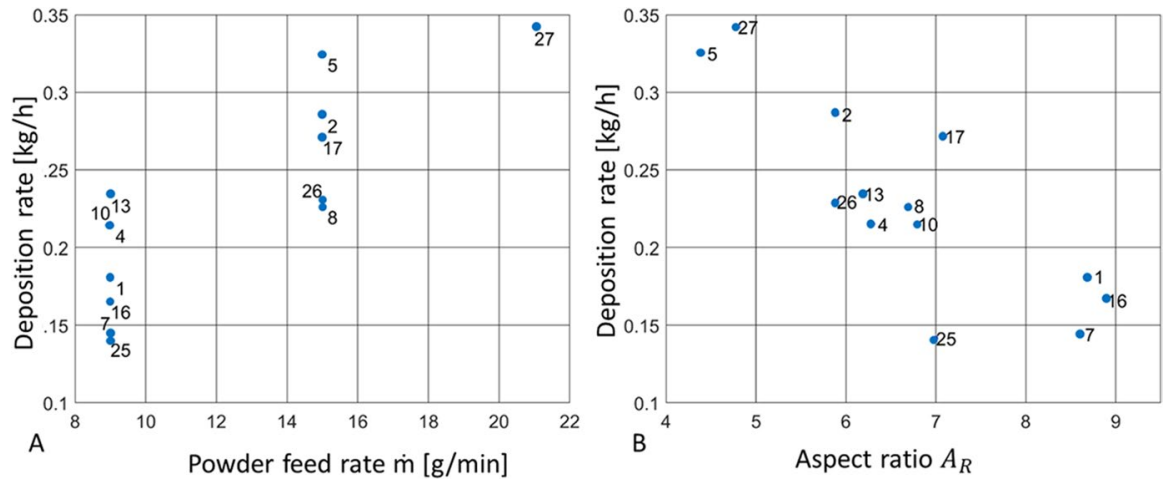

Fig. 6 Correlation between the deposition rate and the powder feed rate and aspect ratio of the fabricated sample (adequate cladability group) 

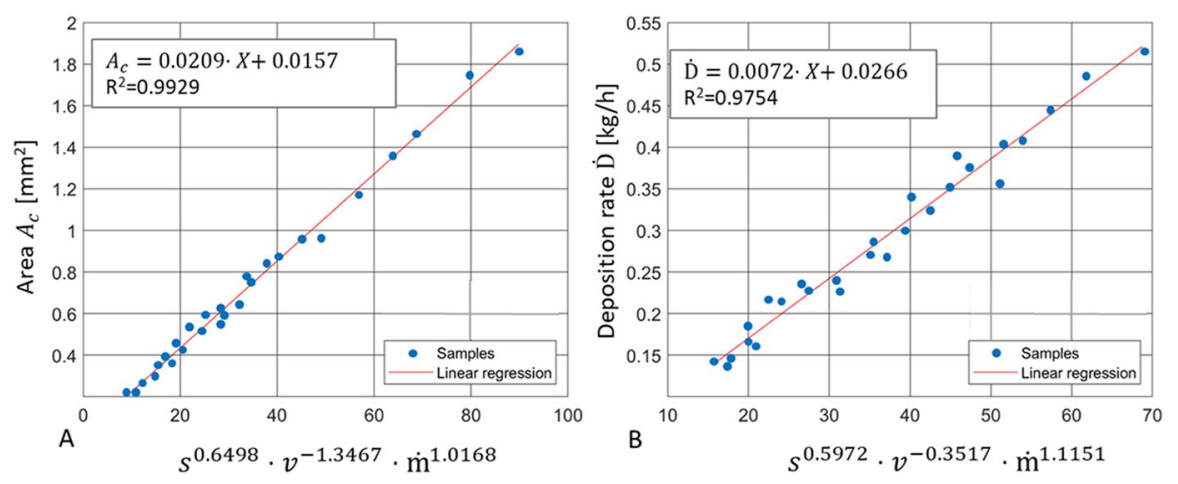

Fig. 7 Correlation of clad area $A_{c}\left[\mathrm{~mm}^{2}\right]$ and deposition rate $\dot{\mathrm{D}}[\mathrm{kg} / \mathrm{h}]$ with combined parameter $s^{\alpha} v^{\beta} \dot{\mathrm{m}}^{\gamma}$. Units of independent variables are $s[\mathrm{~mm}], v[\mathrm{~mm} / \mathrm{min}]$, and $\dot{\mathrm{m}}[\mathrm{g} / \mathrm{min}]$
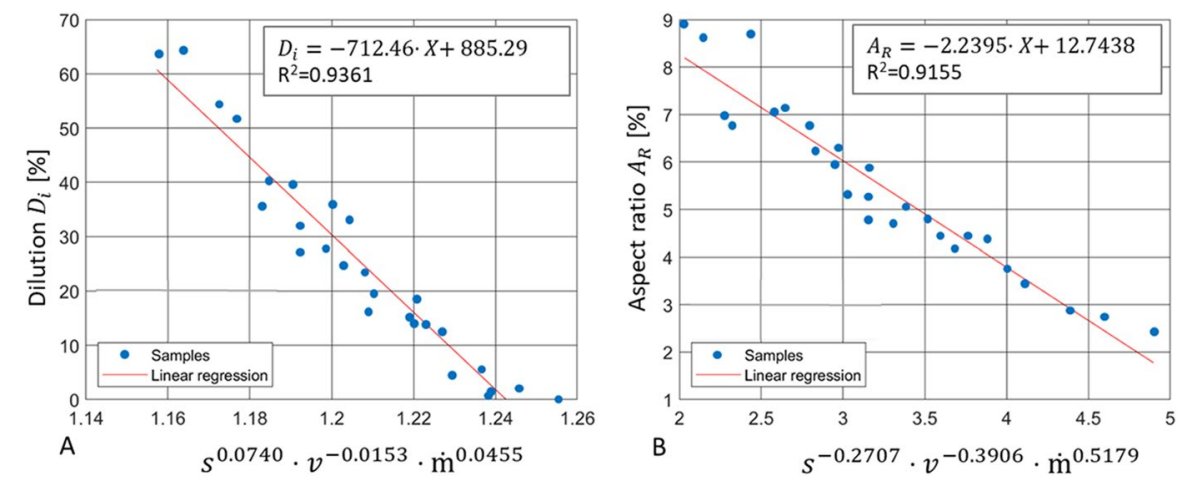

Fig. 8 Dependence of the dilution $D_{i}[\%]$ and aspect ratio $A_{R}$ of the deposited track on the combined parameter of $s^{\alpha} v^{\beta} \dot{\mathrm{m}}^{\gamma}$. Units of independents variables are $s[\mathrm{~mm}], v[\mathrm{~mm} / \mathrm{min}]$, and $\mathrm{m}[\mathrm{g} / \mathrm{min}]$

less probability of porosity formation between the overlapped layer at a higher aspect ratio value. This point will be discussed in the next section.

It can be concluded from these results that the laser spot size of $2.5 \mathrm{~mm}$ at the given laser power of $1200 \mathrm{~W}\left(I=244.5 \mathrm{~W} / \mathrm{mm}^{2}\right)$ is suitable for being chosen to construct the processing map. This intensity value provides sufficient heat input for the proper metallurgical bonding. Besides, it offers the possibility of selection of a broader range of powder feed rate and scan speed $(\dot{\mathrm{m}}=9-15 \mathrm{~g} / \mathrm{min} ; v=600-1400$ $\mathrm{mm} / \mathrm{min})$.

\section{Regression Analysis}

The linear regression analysis presents a good correlation of $\mathrm{R}^{2}>0.9$ for all geometrical parameters studied of aspect ratio and dilution (corresponded to $A_{c}, A_{m}$, w 
and $\mathrm{h}$ ), as well as the deposition rate $\dot{\mathrm{D}}$ (cf. Figs. 7 and 8). The optimum combined parameters to linearly correlated $A_{c}$ is described by:

$$
A_{c}=0.0209 \cdot s^{0.6498} \cdot v^{-1.3467} \cdot \dot{\mathrm{m}}^{1.0168}+0.0157
$$

where the regression line has a high correlation factor of 0.99, as shown in Fig. 7A. Accordingly, the deposition rate, which is calculated based on the clad area, is linearly correlated with the correlation factor of 0.97 , described by:

$$
\dot{\mathrm{D}}=0.0072 \cdot s^{0.5972} \cdot v^{-0.3517} \cdot \dot{\mathrm{m}}^{1} .1151+0.0266
$$

The dilution is found with a linear regression coefficient of $\mathrm{R}^{2}=0.93$, described by:

$$
D_{i}=-712.46 \cdot s^{0.0740} \cdot v^{-0.0153} \cdot \dot{\mathrm{m}}^{0.0455}+885.29
$$

according to the linear statistical dependence of the dilution, shown in Fig. 8A. It approximates that dilution occurs when a combination of parameters $\mathrm{X}\left(s^{0.0740} v^{-0.0153} \dot{\mathrm{m}}^{0.0455}\right)$ is equal to 1.24 , so below this value, insufficient melting or detachment of the clad layer occurs.

The aspect ratio is linearly correlated with the correlation factor of $R^{2}=0.93$, described by:

$$
A_{R}=-2.2395 \cdot s^{-0.2707} \cdot v^{-0.3906} \dot{\mathrm{m}}^{0.5179}+12.7438
$$

The linear regression equation of the aspect ratio presents that $\dot{m}$ has a significant effect on the resulting aspect ratio

\section{Process Map for Material Deposition}

Based on the regression Eqs. (8-11) developed in the previous section, the processing map for depositing the powder material EN X3CrNiMo13-4 is constructed, as shown in Fig. 9. This map represents the deposition rate and the geometrical characteristics of the single clad tracks to their applied processing parameters of scan speed and powder feed rate, at the laser power and the spot diameter of $1200 \mathrm{~W}$ and $2.5 \mathrm{~mm}$, respectively. The background color legend shows the deposition rate as it increases with $\dot{\mathrm{m}}$, following the function $v^{-0.3517} \dot{\mathrm{m}}^{1.151}$ (cf. Eq. (9)). The parabolicdashed curves for six constant values of deposition rate $(\dot{\mathrm{D}}=0.45 \mathrm{~kg} / \mathrm{h}, 0.4 \mathrm{~kg} / \mathrm{h}$, $0.35 \mathrm{~kg} / \mathrm{h}, 0.3 \mathrm{~kg} / \mathrm{h}$, and $0.25 \mathrm{~kg} / \mathrm{h}$ ) were plotted. Dilution decreases on a curved path following the function $v \alpha \dot{\mathrm{m}}^{3}$ (cf. Fig. 8).

The two solid, parabolic red curves on the processing map show the recommended boundary values of the dilution. Selecting a dilution lower than $14 \%$ causes insufficient metallurgical bonding on the edges of the overlapping tracks, and dilution above $35 \%$ is not desirable due to downgrading the deposition efficiency. The aspect ratio increases with $\dot{\mathrm{m}}$ due to the higher clad height. The four constant values of aspect ratio $\left(A_{R}=4,5\right.$, and 7) were plotted on the map. The aspect ratio line $A_{R}=4$ represents the boundary of parameter choice since inter-run porosity will 


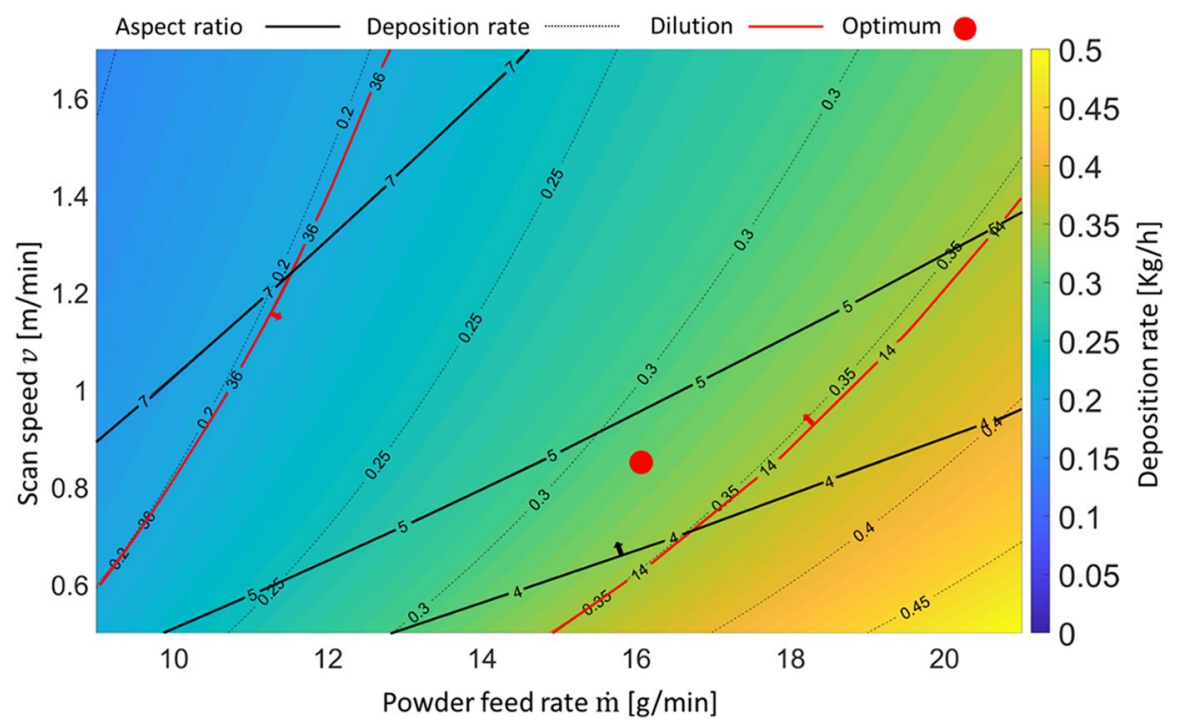

Fig. 9 Process field for deposition of material EN X3CrNiMo13-4 (1.4313) at $\mathrm{P}=1200 \mathrm{~W}$ and $\mathrm{s}=2.5$ $\mathrm{mm}$. Dilution between $14 \%$ and $36 \%$ (solid parabolic-red curves) and aspect ratio $A_{R}>4$ are the boundaries for defect-free depositions, shown with arrays. The red circle shows the area of optimum parameter combination concerning deposition rate and melting efficiency

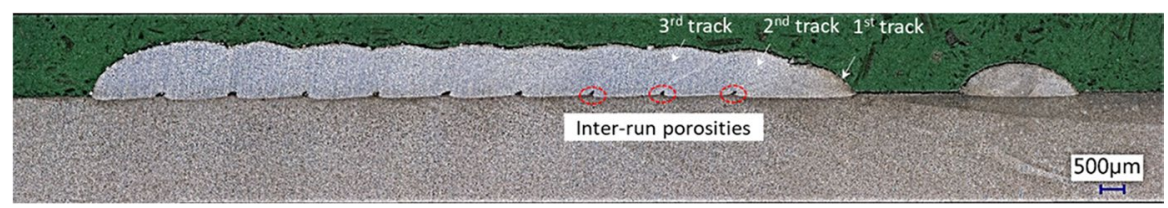

Fig. 10 Single track and ten overlapped layers (60\% overlap), deposited from material EN X3CrNiMo13-4 (1.4313), with the laser parameter of $\mathrm{P}=1200 \mathrm{~W}, v=600 \mathrm{~mm} / \mathrm{min}$, and $\dot{\mathrm{m}}=15 \mathrm{~g} / \mathrm{m}$. The aspect ratio of 4 and dilution of $14.1 \%$ result in inter-run porosities between layers, shown by dotted red circles

occur between the overlapping layers at $A_{R} \leq 4$. Controlling the aspect ratio facilitates avoiding the inter-run porosity between overlapping tracks.

Figure 10 shows a single track and multiple layers fabricated with a parameter combination of sample N.5 ( $v=600 \mathrm{~mm} / \mathrm{min}$ and $\dot{\mathrm{m}}=15 \mathrm{~g} / \mathrm{min})$. In this sample, the aspect ratio value is 4 , which leads to the porosity between layers, as three of them are shown with red-dotted circles. As it was discussed, this is due to the fact that a layer formed by overlapping tracks is thicker than that of a single track, and a portion of laser energy is consumed by re-melting the previous clad track on the side.

There is a relatively large operating region for the deposition of a layer without bonding error, as illustrated in the map (Fig. 9). The optimum process combination among the examined variables concerning maximum deposition rate and adequate cladability can be located approximately at the intersection of the $\dot{\mathrm{D}}$ curve of 
$0.3 \mathrm{~kg} / \mathrm{h}$ and aspect ratio line of 5 , as shown on the map with a red circle. If the scan speed and powder feed rate axes are assumed to be a vertical and horizontal axis, respectively, increasing the scan speed along the vertical axis minimizes the productivity, and increasing the powder feed rate along the horizontal axis can offset the process to the risky region (risk of bonding error). The upturn of these values along parabolic-dashed curves of $0.3 \mathrm{~kg} / \mathrm{h}$ can downgrade the powder melting efficiency.

\section{Conclusion and Outlook}

In this study, the effects of main Laser DMD process parameters on track geometry of material EN X3CrNiMo13-4 (1.4313) were investigated to define the optimum laser parameter combination to achieve a maximum deposition rate. The Taguchi method is employed to perform the experiment's design to test a wide range of processing parameters. Accordingly, the effects of the laser power, scan speed, powder flow rate, and spot diameter on track geometrical quality and productivity were discussed. The regression analysis was conducted to derive correlations between the combined set of main parameters $(s, v, \dot{\mathrm{m}})$ and the characteristic of the clad geometries ( $A_{R}$ and $D_{i}$ ) and deposition rate. Accordingly, a prediction process map was developed using the regression analysis in connection with deposition rate, aspect ratio, and dilution rate. The key points are listed below:

- The laser spot size of $2.5 \mathrm{~mm}$ at the given laser power of $1200 \mathrm{~W}$ provides sufficient heat input (laser intensity of $244.5 \mathrm{~W} / \mathrm{mm}^{2}$ ) to melt the powder and the substrate at a wide range of powder feed rate and scan speed selection possibility.

- The linear regression analysis presented a good correlation of $\mathrm{R}^{2}>0.9$ for all geometrical parameters studied of $A_{R}$, dilution $D_{i}$, and the deposition rate $\dot{\mathrm{D}}$. The optimum combined parameters to linearly correlated $\dot{D}$ is presented in Eq. (9). The combined parameters with a linear regression coefficient of $\mathrm{R}^{2}=0.93$ were found according to the linear statistical dependence of the dilution, given by Eq. (10). The linear regression of $A_{R}$ presented in Eq. (11), shown that $\dot{\mathrm{m}}$ has a significant effect on the result of $A_{R}$.

- The developed process map provided a range of suitable parameters, able to deposit layers with low dilution, strong metallurgical bonding, and defect-free layers. Dilution between $14 \%$ and $36 \%$ and aspect ratio $A_{R}>4$ were the boundaries for defect-free depositions. It specified the optimum parameter combination of scan speed $v$ and powder feed rate $\dot{m}$ with regards to the maximum deposition rate achievement. They can be in the range of $800 \leq v \leq 1000 \mathrm{~mm} / \mathrm{min}$ and $14 \leq \dot{\mathrm{m}} \leq 16 \mathrm{~g} / \mathrm{min}$ at $1.2 \mathrm{~kW}$ laser power. The absolute deposition rate $\dot{\mathrm{D}}$ was $0.33-0.35 \mathrm{~kg} / \mathrm{h}$ in this level of laser power.

- The constructed map showed that the powder feed rate and scan speed directly affect the resulting deposition rate. However, excesses scan speed (above the optimum parameter set) can lead to downgrading the deposition rate and powder melting efficiency. Besides, the excess powder feed rate can lead the process to the risky region of bonding error between overlapped tracks. 
Acknowledgements This work was financially sponsored by the Swiss innovation agency Innosuisse [Grant number 27436.1 PFNM-NM], which is gratefully acknowledged.

Author Contributions M. Dalaee (Design, perform and date analysis, wrote the paper); E. Cerrutti (Contributed data and analysis tools); I. Dey (Editing); C. Leinenbach (Improvement paper structure, editing, proofreading); K. Wegener (Improvement paper structure, editing, proofreading Final approval of the version).

Funding Open access funding provided by Swiss Federal Institute of Technology Zurich. This work was financially sponsored by the Swiss innovation agency Innosuisse [Grant number 27436.1 PFNM-NM], which is gratefully acknowledged.

\section{Declarations}

Conflict of Interest The authors declare that they have no conflict of interest.

Ethical Approval The authors declare that there is no conflict of ethical responsibilities.

Consent to Participate and publish: The authors confirm it.

Open Access This article is licensed under a Creative Commons Attribution 4.0 International License, which permits use, sharing, adaptation, distribution and reproduction in any medium or format, as long as you give appropriate credit to the original author(s) and the source, provide a link to the Creative Commons licence, and indicate if changes were made. The images or other third party material in this article are included in the article's Creative Commons licence, unless indicated otherwise in a credit line to the material. If material is not included in the article's Creative Commons licence and your intended use is not permitted by statutory regulation or exceeds the permitted use, you will need to obtain permission directly from the copyright holder. To view a copy of this licence, visit http://creativecommons.org/licen ses/by/4.0\%.

\section{References}

1. Soffel, F., Eisenbarth, D., Wegener, K.: Effect of clad height, substrate thickness and scanning pattern on cantilever distortion in direct metal deposition. Int J Adv Manuf Technol 117, 2083-2091 (2021). https://doi.org/10.1007/s00170-021-06925-7

2. Rashkovets, M., Mazzarisi, M., Nikulina, A., Casalino, G.: Analysis of laser direct stainless steel powder deposition on Ti6Al4V substrate. Mater. Lett. 274, 128064 (2020)

3. Cavaliere P., Silvello A., Perrone A.: Additive Manufacturing by Laser Cladding: State of the Art. In: Cavaliere P. (eds) Laser Cladding of Metals. Springer, Cham. 2021. https://doi.org/10.1007/ 978-3-030-53195-9_2

4. Yan, L., Chen, Y., Liou, F.: Additive manufacturing of functionally graded metallic materials using laser metal deposition. Addit. Manuf. 31, 100901 (2020). https://doi.org/10.1016/j.addma.2019. 100901

5. Bhardwaj, T., Shukla, M.: Laser additive manufacturing- Direct energy deposition of Ti-15Mo biomedical alloy: artificial neural network based modeling of track dilution. Lasers Manuf. Mater. Process. 7(3), 245-258 (2020). https://doi.org/10.1007/s40516-020-00117-z

6. Singh, A., Kapil, S., Das, M.: A comprehensive review of the methods and mechanisms for powder feedstock handling in directed energy deposition. Addit. Manuf. 35, 101388 (2020). https://doi.org/ 10.1016/j.addma.2020.101388

7. Dalaee, M.T., Gloor, L., Leinenbach, C., Wegener, K.: Experimental and numerical study of the influence of induction heating process on build rates Induction Heating-assisted laser Direct Metal Deposition (IH-DMD). Surf. Coat. Technol. 384, 125275 (2020) 
8. Dalaee, M., Cheaitani, F., Arabi-Hashemi, A., Rohrer, C., Weisse, B., Leinenbach, C., Wegener, K.: Feasibility study in combined direct metal deposition (DMD) and plasma transfer arc welding (PTA) additive manufacturing. Int. J. Adv. Manuf. Technol. 106(9), 4375-4389 (2020)

9. Liu, Y., Ding, Y., Yang, L., Sun, R., Zhang, T., Yang, X.: Research and progress of laser cladding on engineering alloys: A review. J. Manuf. Process. 66, 341-363 (2021)

10. Errico, V., Campanelli, S.L., Angelastro, A., Mazzarisi, M., Casalino, G.: On the feasibility of AISI 304 stainless steel laser welding with metal powder. J. Manuf. Process. 56, 96-105 (2020). https:// doi.org/10.1016/j.jmapro.2020.04.065

11. Campanelli, S.L., Angelastro, A., Signorile, C.G., Casalino, G.: Investigation on direct laser powder deposition of $18 \mathrm{Ni}$ (300) marage steel using mathematical model and experimental characterisation. Int. J. Adv. Manuf. Technol. 89(1), 885-895 (2017)

12. Ascari, A., Lutey, A.H.A., Liverani, E., Fortunato, A.: Laser directed energy deposition of bulk 316L stainless steel. Lasers Manuf. Mater. Process. 7(4), 426-448 (2020). https://doi.org/10.1007/ s40516-020-00128-w

13. Henry, M., Fearon, E., Watkins, K., Dearden, G.: The laser cladding of hastalloy to critical surfaces of stainless steel components. In: International Congress on Applications of Lasers \& ElectroOptics, vol 1. Laser Institute of America, pp 631-640 (2001)

14. Sun, S., Brandt, M., Harris, J., Durandet, Y.: The influence of stellite 6 particle size on the intertrack porosity in multi-track cladding. Surf. Coat. Technol. 201(3-4), 998-1005 (2006)

15. Dass, A., Moridi, A.: State of the art in directed energy deposition: From additive manufacturing to materials design. Coatings 9(7), 418 (2019)

16. Toyserkani, E., Khajepour, A., Corbin, S.F.: Laser Cladding. CRC Press, Boca Raton (2004)

17. Colaco, R., Costa, L., Guerra, R., Vilar, R.: A simple correlation between the geometry of laser cladding tracks and the process parameters. In: Laser Processing: surface treatment and film deposition, pp. 421-429. Springer, Berlin (1996)

18. Wirth, F.: Process understanding, modeling and predictive simulation of laser cladding. ETH Zurich, PHD Desseration (2018)

19. Mianji, Z., Kholopov, A.A., Binkov, I.I., Kiani, A.: Numerical simulation of thermal behavior and experimental investigation of thin walls during direct metal deposition of $316 \mathrm{~L}$ stainless steel powder. Lasers Manuf. Mater. Process. (2021). https://doi.org/10.1007/s40516-021-00155-1

20. Ansari, M., Razavi, R.S., Barekat, M.: An empirical-statistical model for coaxial laser cladding of NiCrAlY powder on Inconel 738 superalloy. Opt. Laser Technol. 86, 136-144 (2016)

21. Li, Y.-X., Zhang, P.-F., Bai, P.-K., Zhao, Z.-Y., Liu, B.: Analysis of geometrical characteristics and properties of laser cladding $85 \mathrm{wt} \% \mathrm{Ti}+15 \mathrm{wt} \% \mathrm{TiBCN}$ powder on 7075 aluminum alloy substrate. Materials 11(9), 1551 (2018)

22. Pacheco, J.T., da Silva, L.J., Barbetta, L.D., Ferreira, H.S., Veiga, M.T., Forni, R., Teixeira, M.F.: Laser cladding of stellite-6 on AISI 316 L austenitic stainless steel: empirical-statistical modeling and parameter optimization. Lasers Manuf. Mater. Process. 8(1), 1-14 (2021)

23. Bax, B., Rajput, R., Kellet, R., Reisacher, M.: Systematic evaluation of process parameter maps for laser cladding and directed energy deposition. Addit. Manuf. 21, 487-494 (2018). https://doi.org/10. 1016/j.addma.2018.04.002

24. Shayanfar, P., Daneshmanesh, H., Janghorban, K.: Parameters optimization for laser cladding of inconel 625 on ASTM A592 steel. J. Mater. Res. Technol. 9(4), 8258-8265 (2020). https://doi.org/ 10.1016/j.jmrt.2020.05.094

25. Erfanmanesh, M., Abdollah-Pour, H., Mohammadian-Semnani, H., Shoja-Razavi, R.: An empiricalstatistical model for laser cladding of WC-12Co powder on AISI 321 stainless steel. Opt. Laser Technol. 97, 180-186 (2017). https://doi.org/10.1016/j.optlastec.2017.06.026

Publisher's Note Springer Nature remains neutral with regard to jurisdictional claims in published maps and institutional affiliations. 


\section{Authors and Affiliations}

Mohammad Dalaee $^{1,2}$ (D) Eduardo Cerrutti $^{1} \cdot$ Indira Dey $^{1,2}$.

Christian Leinenbach $^{3} \cdot$ Konrad Wegener $^{1}$

Eduardo Cerrutti

eduardo.cerrutti@gmail.com

Indira Dey

Dey@inspire.ethz.ch

Christian Leinenbach

christian.leinenbach@empa.ch

Konrad Wegener

wegener@iwf.mavt.ethz.ch

1 Institute of Machine Tools \& Manufacturing (IWF), ETH Zürich, Zürich, Switzerland

2 inspire AG, Zürich, Switzerland

3 Empa, Swiss Federal Laboratories for Materials Science and Technology, Dübendorf, Switzerland 